\title{
Antagonistic Effect of Se on the T-2 Toxin-Induced Changes in the Ultrastructure and Mitochondrial Function of Cultured Chicken Embryonic Chondrocytes*
}

\author{
Zhi-Huan LIN, ${ }^{* *}$ Sheng-Guang LI, Lian-Ying WU, \\ San SuN, and Qi-Wu LU \\ Institute of Biophysics, Academia Sinica, Beijing 100101, China
}

(Received March 15, 1994)

\begin{abstract}
Summary T-2 toxin extracted from a strain of Fusarium tricinctum has a structure similar to that of the Fusarium mycotoxin found in grains in Kaschin-Beck Disease endemic areas. By scanning and freeze-fracture transmission electron microscope observations, we found that $0.01 \mathrm{ppm}$ $\mathrm{T}-2$ toxin caused a significant decrease of collagen microfibrils in the extracellular matrix and intramembrane particles on the protoplasmic face of the plasma membrane of cultured chicken embryonic chondrocytes. In addition, T-2 toxin obviously reduced the activities of mitochondrial cytochrome $c$ oxidase and $\mathrm{H}^{+}$-ATPase, and the sensitivity of the latter to oligomycin, of chondrocytes. In our experiment we found that, when $0.01 \mathrm{ppm} \mathrm{T-2}$ toxin was added in the presence of $1 \mathrm{ppm}$ $\mathrm{Na}_{2} \mathrm{SeO}_{3}$ in the culture, the decreases in collagen microfibril and intramembrane particle numbers could not be seen and that the activities of cytochrome $c$ oxidase and $\mathrm{H}^{+}$-ATPase and the sensitivity of the latter to oligomycin were less decreased. Furthermore, the experimental result showed that the effect of Se on chondrocytes is concentration dependent and that $1 \mathrm{ppm}$ of $\mathrm{Na}_{2} \mathrm{SeO}_{3}$ is the optimal concentration. Thus we conclude that Se deficiency may be an important factor for the pathogenesis of Kaschin-Beck disease.
\end{abstract}

Key Words: Kaschin-Beck disease, selenium, T-2 toxin, cultured embryo chondrocytes, extracellular matrix

Kaschin-Beck disease (KBD) is a deformed osteoarthropathy. The main pathological changes are the necrosis of cartilage, early calcification, and disorder of bone growth. Many hypotheses have been presented on the pathogenesis of this disease, but it remains unsolved up to now. The hypothesis adopted in this paper

\footnotetext{
* Project supported by the 7th Five-year Plan for Scientific Research in China

** To whom correspondence should be addressed.
} 
is that KBD is caused by a kind of toxin produced by a type of fungus that grows in the food or grain consumed by humans, thus leading to mycotoxin poisoning and resulting in KBD formation. This has been called the "dietary fungi intoxication hypothesis" [1]. On comprehensive scientific survey of Yun-Shou County, an endemic area of KBD, a high content of Fusarium was detected in various crops [2]. Fusarium toxin was also found in the corn of other endemic areas [3]. In order to investigate the effect of Fusarium toxin on the target tissue of KBD, i.e., chondrocytes, we used the most potent typical toxin T-2 [4], extracted from a strain of Fusarium tricinctum, to attack the cultured chicken embryo chondrocytes directly, so as to see its effects on the ultrastructure and mitochondrial function of these cells.

The close relation between $\mathrm{KBD}$ and $\mathrm{Se}$ is evidenced by the fact that in endemic areas, Se contents of water, soil, crops and patients' blood and hair are all low [5] and that Se supplementation has an obvious effect of controlling KaschinBeck disease clinically [6-8]. Wo and Yang [9] reported that Se has a significant effect of preventing the "aging" of human erythrocyte membranes, and they proposed that $\mathrm{Na}_{2} \mathrm{SeO}_{3}$ may stabilize the membrane cytoskeleton of human erythrocytes $[10]$.

In this paper, we describe experiments on the effect of $\mathrm{T}-2$ toxin on cultured chondrocytes and our investigation into whether Se at optimal concentration has a preventive or antagonistic effect on the T-2 toxin-induced ultrastructural and mitochondrial function changes in these cells.

\section{MATERIALS AND METHODS}

Culture of chondrocytes. The culture procedure was described previously [11]. The leg (thighbone and shinbone) and hipbone of 12-day chick embryos were stripped and digested with $0.25 \%$ trypsin in Simm's buffer $(\mathrm{pH} 7.2)$ at $37^{\circ} \mathrm{C}$ for $15 \mathrm{~min}$ and then washed 2 times with the same buffer. After the diaphysis had been removed, the remaining epiphysis and the whole hipbone were cut into small pieces with a pair of scissors and were digested again with $0.25 \%$ trypsin for $20 \mathrm{~min}$, and then rinsed with Ham's F-12 (pH 7.2) (GIBCO Laboratories Life Technologies Inc., Grand Island, NY) 2-3 times. The chondrocytes were dispersed and cultured in a closed system (a sterilized glass vial with cover glass) that was incubated in a $37^{\circ} \mathrm{C}$ incubator. After a 48 -h incubation, $\mathrm{Na}_{2} \mathrm{SeO}_{3}$ was added to the culture media at a concentration of $0,1,2$, or $4 \mathrm{ppm}$, respectively, and the cultures were then incubated for another 2 days.

Specimen preparation for scanning electron microscopy (SEM) observation. Specimen preparation was done as described earlier [12] with some modification. After the chondrocytes had been cultured for 4 days, the cover glass bearing the chondrocytes was removed from the glass vial that contained it; and the chondrocytes were treated with $0.5 \%$ Triton X-100 in PEM buffer containing PIPES, $100 \mathrm{~mm}$; EGTA, $1 \mathrm{~mm} ; \mathrm{MgCl}_{2}, 0.5 \mathrm{~mm}$; pH 6.9 for $15 \mathrm{~min}$. Next the cells were fixed 
with $2 \%$ glutaraldehyde in PEM buffer for $15 \mathrm{~min}$, and postfixed with $1 \% \mathrm{OsO}_{4}$ in PBS buffer ( $\mathrm{pH} \mathrm{7.2)} \mathrm{for} 30 \mathrm{~min}$. The sample was dehydrated by passage through a series of ethanols, dried in a critical-point drier, and coated with gold with an ion sputter JEC-1100 (JEOL, Tokyo). The specimens were examined under a JSM-35 CF (JEOL, Tokyo) scanning electron microscope.

Specimen preparation for freeze-fracture transmission electron microscopy (TEM) observation. Freeze-fracture electron microscopy was performed according to Hwang et al. [13] T-S buffer solution (Tris-HCl, $10 \mathrm{~mm}$; sucrose, $0.25 \mathrm{M} ; \mathrm{pH}$ 7.4) was added to the vial in which chondrocytes had grown on the wall and the culture medium had been decanted. The chondrocytes were then scraped from the vial wall, and the vial was washed twice with the T-S buffer. The scraping and washing suspensions were combined, and the pooled cells were centrifuged at $540 \times g$ for 7 min with a type [x]-64-01 centrifuge (Beijing Medical Instruments Factory, Beijing). After removal of the supernatant with a dropper, the cell pellet was fixed with $2.5 \%$ glutaraldehyde in T-S buffer for more than $2 \mathrm{~h}$, after which the fixative was washed out. The pellet was next resuspended in $20 \%$ glycerolphosphate buffer for about $12 \mathrm{~h}$, and the cells were subsequently collected by centrifugation at $560 \times g$. The specimens were frozen in liquid nitrogen. According to the routine method, platinum-carbon freeze-fracture replicas were prepared with a BAF-400 D Freeze etching system (Balzers, Liechtenstein). The replicas were examined under a JEM-100 CX transmission electron microscope (JEOL, Tokyo).

Preparation of homogenates of chondrocytes. The homogenates of chondrocytes cultured in different concentrations of Se were prepared respectively according to the following procedure: The chondrocytes were scraped from the culture vial into T-S buffer. The vial was then rinsed with T-S buffer twice. The scraping and rinsing suspensions were combined and centrifuged at $540 \times g$ for 7 min. After the supernatant had been discarded, T-S buffer was added to the cell pellet; and the latter was disrupted ultrasonically with a LABSONIC $2000 \mathrm{~B}$. Braun (Melsungen). The homogenizing solution was centrifuged at $560 \times g$ for 7 min with a RPR 20-3-849 centrifuge (Hitachi, Tokyo). The supernatant was taken for the chondrocyte homogenate.

Enzymes measurements. Activities of cytochrome $c$ oxidase [14], succinic dehydrogenase [15], and $\mathrm{H}^{+}$-ATPase, and sensitivity of $\mathrm{H}^{+}$-ATPase to oligomycin [16] were determined as referenced.

\section{RESULTS AND DISCUSSION}

The effect of different concentrations of Se on the ultrastructure and mitochondrial function of cultured chicken embryo chondrocytes

To determine an adequate and maximal safe concentration of Se in relation to its potency for the growth, multiplication and integrity of structure and function of the cultured chondrocytes is very important. The nutritional action of the trace element Se is compatible with Bertrand's rule [17]; i.e., in the nutritional curve of 
Se, the plateau representing the maintenance of optimal function is narrow. Deficiency effect will occur when the concentration of $\mathrm{Se}$ is below the plateau range while potential toxicity will occur when the concentration of Se exceeds the plateau range. Besides, the protective effect of Se on stabilization of the membrane cytoskeleton of human erythrocytes is concentration dependent, as reported by Yang and Yang [18]. Wu et al. [19] reported their study on the effect of Se on chondrocyte ultrastructure, demonstrated that the effect of this trace element is also concentration dependent.

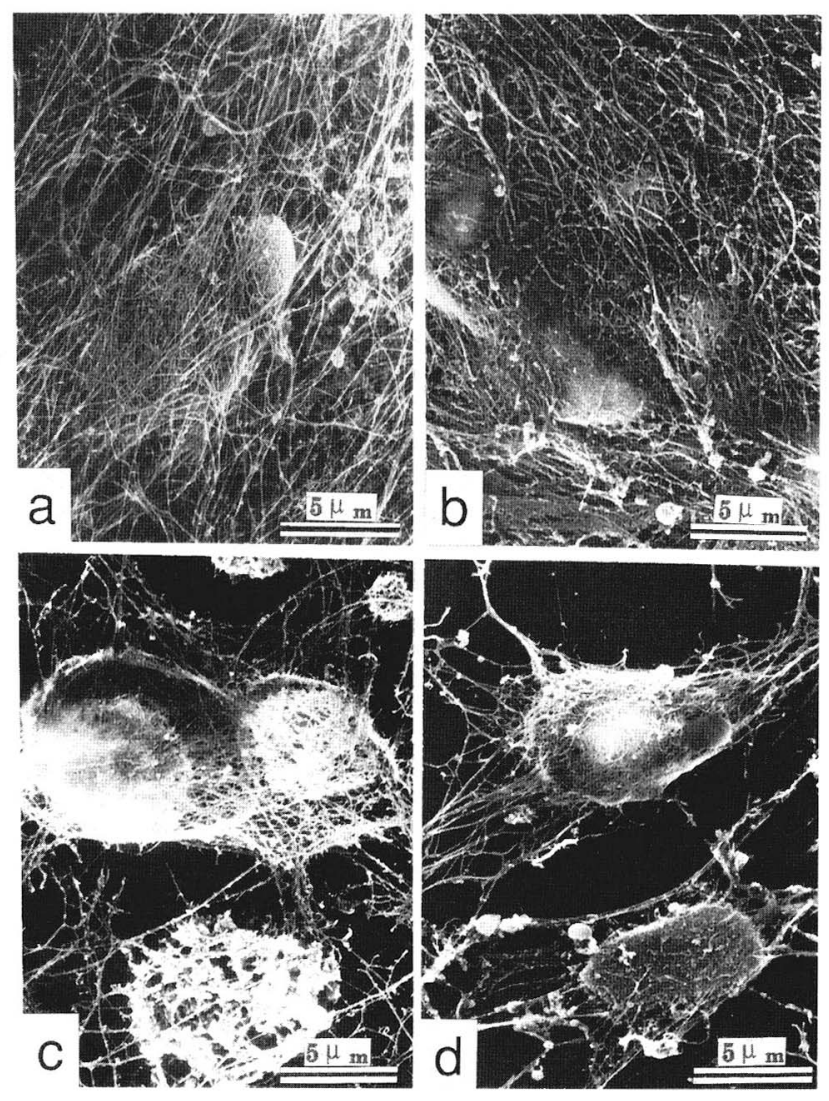

Fig. 1. Scanning electron microscope observations showing the cytoskeleton and extracellular matrix from 2-day cultures of chicken embryonic chondrocytes in medium containing different concentrations of $\mathrm{Na}_{2} \mathrm{SeO}_{3}$. (a) Control: Showing collagen microfibrils of extracellular matrix of chicken embryonic chondrocytes. (b) Showing the increase in collagen microfibril number of extracellular matrix of chicken embryonic chondrocytes cultured with 1 ppm $\mathrm{Na}_{2} \mathrm{SeO}_{3}$. (c) Showing the decrease in collagen microfibril amount of extracellular matrix of chicken embryonic chondrocytes cultured with $2 \mathrm{ppm}$ $\mathrm{Na}_{2} \mathrm{SeO}_{3}$. (d) Showing a greater decrease in collagen microfibril amount of extracellular matrix, but no significant change in cytoskeleton, of chicken embryonic chondrocytes cultured with 4 ppm $\mathrm{Na}_{2} \mathrm{SeO}_{3}$. 
By scanning electron microscopy, a highly organized filamentary network surrounding the chondrocytes, i.e., the extracellular collagen microfibrils, could be clearly seen by means of treatment of the specimen with Triton X-100. The chicken embryonic chondrocytes were cultured in the presence of different concentrations of $\mathrm{Na}_{2} \mathrm{SeO}_{3}$. The experimental results indicated that in the presence of $1 \mathrm{ppm}$ $\mathrm{Na}_{2} \mathrm{SeO}_{3}$ the extracellular collagen microfibrils were increased (Fig. 1(b)) compared with the control (Fig. 1(a)). When the concentration of $\mathrm{Na}_{2} \mathrm{SeO}_{3}$ in the culture was increased to 2 and $4 \mathrm{ppm}$ the collagen microfibrils in the extracellular matrix
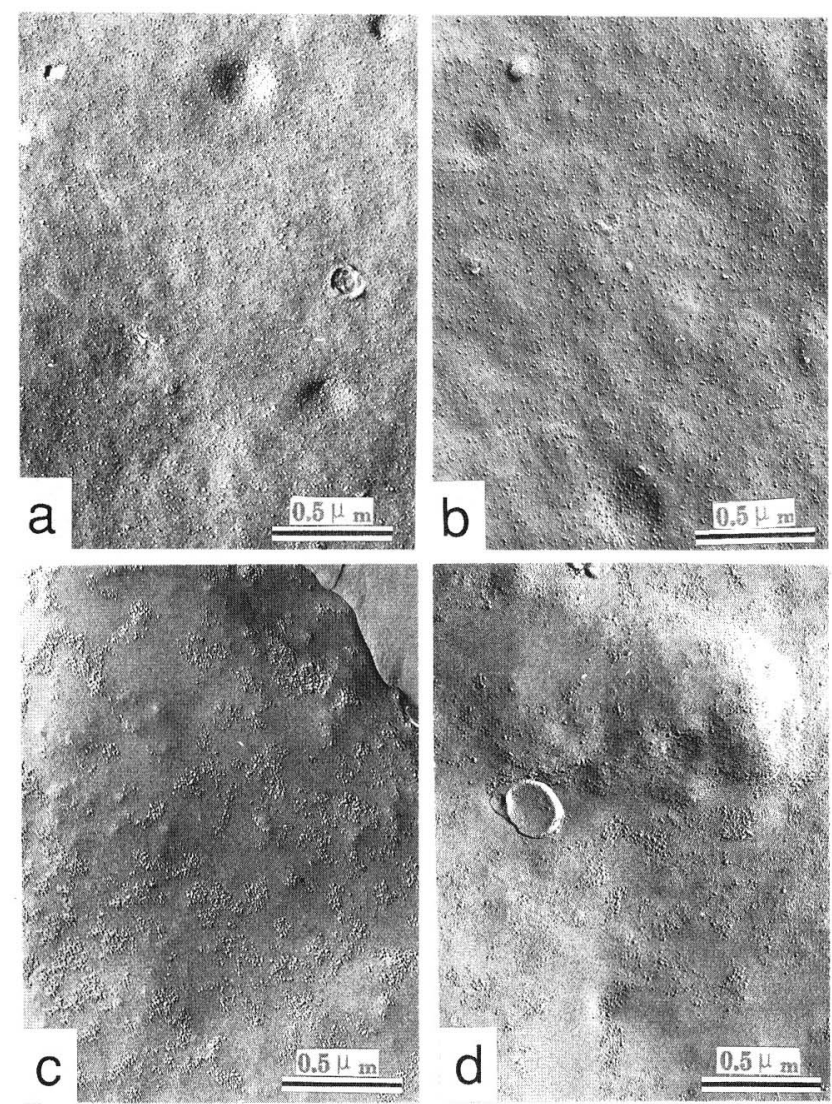

Fig. 2. Freeze-fracture electron micrograph showing the IMPs of a chicken embryonic chondrocyte cultured for two days in medium containing different concentrations of $\mathrm{Na}_{2} \mathrm{SeO}_{3}$. (a) Control: P-face view of plasma membrane of a cell cultured in non-supplemented medium, showing IMPs in a random distribution. (b) The same specimen as in control, but cultured with $1 \mathrm{ppm} \mathrm{Na}_{2} \mathrm{SeO}_{3}$ added, showing IMPs also in random distribution and a little increase of particles. (c) The same specimen as in control, but cultured with $2 \mathrm{ppm} \mathrm{Na}_{2} \mathrm{SeO}_{3}$ added, showing IMPs in obvious aggregation, and appearance of some area without particles occupation. (d) The same specimen as in control, but cultured with $4 \mathrm{ppm} \mathrm{Na}_{2} \mathrm{SeO}_{3}$ added, showing IMPs in obvious aggregation, less particles and some area without particles occupation. 
were significantly decreased as compared with those of the control (Fig. 1(c), (d)). It is known that the chondrocytes possess synthetic capacity to produce collagen microfibrils and then secrete them into the extracellular matrix, thus forming an extended network. The culture medium containing $1 \mathrm{ppm} \mathrm{Na}_{2} \mathrm{SeO}_{3}$ was found to be the best condition for the chondrocytes to synthesize the collagen microfibrils and to secrete them to form a highly organized extracellular matrix. In the case of 2 and 4 ppm $\mathrm{Na}_{2} \mathrm{SeO}_{3}$, the chondrocytes might have been injured [19].

The chondrocytes cultured in the medium containing 1 ppm $\mathrm{Na}_{2} \mathrm{SeO}_{3}$ exhibited evenly distributed intramembrane particles (IMPs) on the protoplasmic (P) face of the membrane, and these particles seemed to be little increased in number compared with the control (Fig. 2(a), (b)). When the concentration of $\mathrm{Na}_{2} \mathrm{SeO}_{3}$ was increased to 2 and $4 \mathrm{ppm}$, the aggregation of IMPs was observed with the concomitant appearance of blank regions without particles (Fig. 2(c), (d)). These IMPs probably represent integral proteins, receptors, etc. Thus, when the $\mathrm{Na}_{2} \mathrm{SeO}_{3}$ concentration is increased to 2 and $4 \mathrm{ppm}$, the aggregation of IMPs probably causes functional injury of the membrane.

The activities of mitochondrial cytochrome $c$ oxidase, succinic dehydrogenase, and $\mathrm{H}^{+}$-ATPase, and oligomycin sensitivity of $\mathrm{H}^{+}$-ATPase were measured in homogenates of the chondrocytes cultured in the presence of different concentrations of Se. The experimental results indicated that for the chondrocytes grown in the medium containing $\mathrm{Na}_{2} \mathrm{SeO}_{3}$ up to $1 \mathrm{ppm}$, the variation of the measured criteria did not exceed $10 \%$ of the control (Fig. 3). This means that the mitochondrial function was not impaired if $\mathrm{Na}_{2} \mathrm{SeO}_{3}$ addition in the culture was kept below

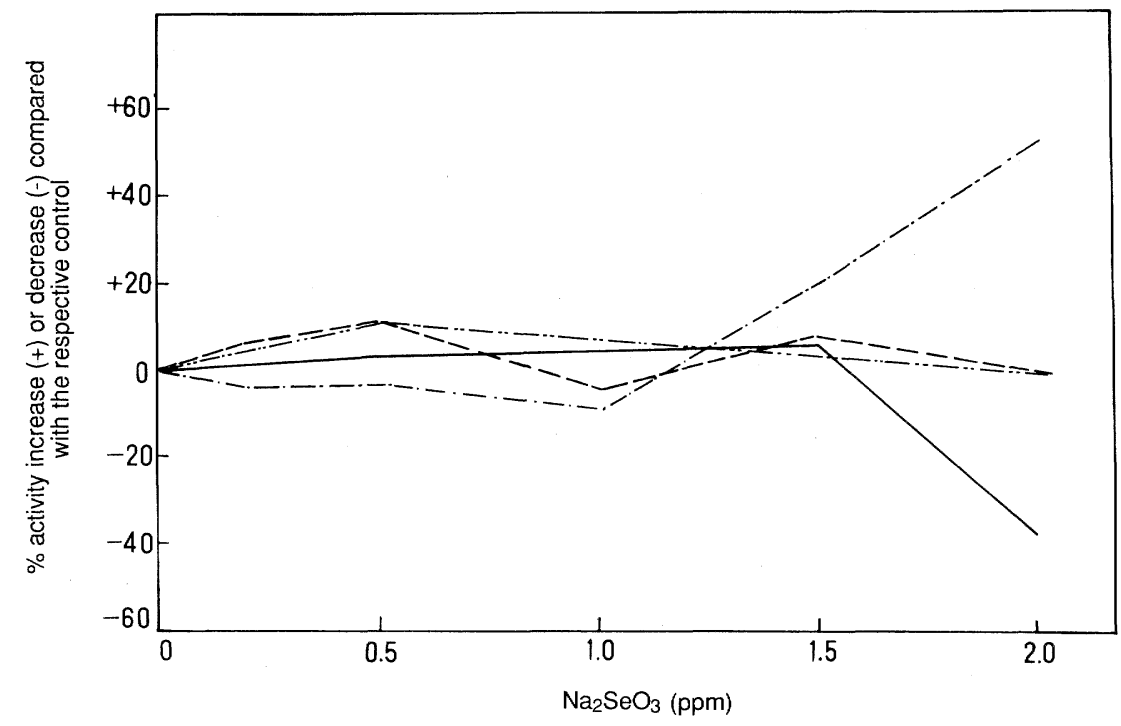

Fig. 3. Effect of different concentrations of Se on the activities of mitochondrial cytochrome $c$ oxidase $(-)$, succinic dehydrogenase $(-\cdots-)$, and $\mathrm{H}^{+}$-ATPase (-- $)$and on the oligomycin sensitivity of $\mathrm{H}^{+}$-ATPase (-.-). 
$1 \mathrm{ppm}$. For this reason, in later experiments on Se antagonism we always used 1 ppm $\mathrm{Na}_{2} \mathrm{SeO}_{3}$ in the culture medium.

Injury effect of T-2 toxin on the ultrastructure and mitochondrial function of cultured chondrocytes

As a test of the "mycotoxin hypothesis," we added T-2 toxin to the medium to culture the chondrocytes. The toxin we used has a structure similar to that of the Fusarium species found in grains in $\mathrm{KBD}$-endemic areas. T-2 toxin is very stable at room temperature, and its toxic potency is not decreased even if it is heated to $200^{\circ} \mathrm{C}$ for $1 \mathrm{~h}$. Three different concentrations, $0.004,0.01$, and $0.04 \mathrm{ppm}$,
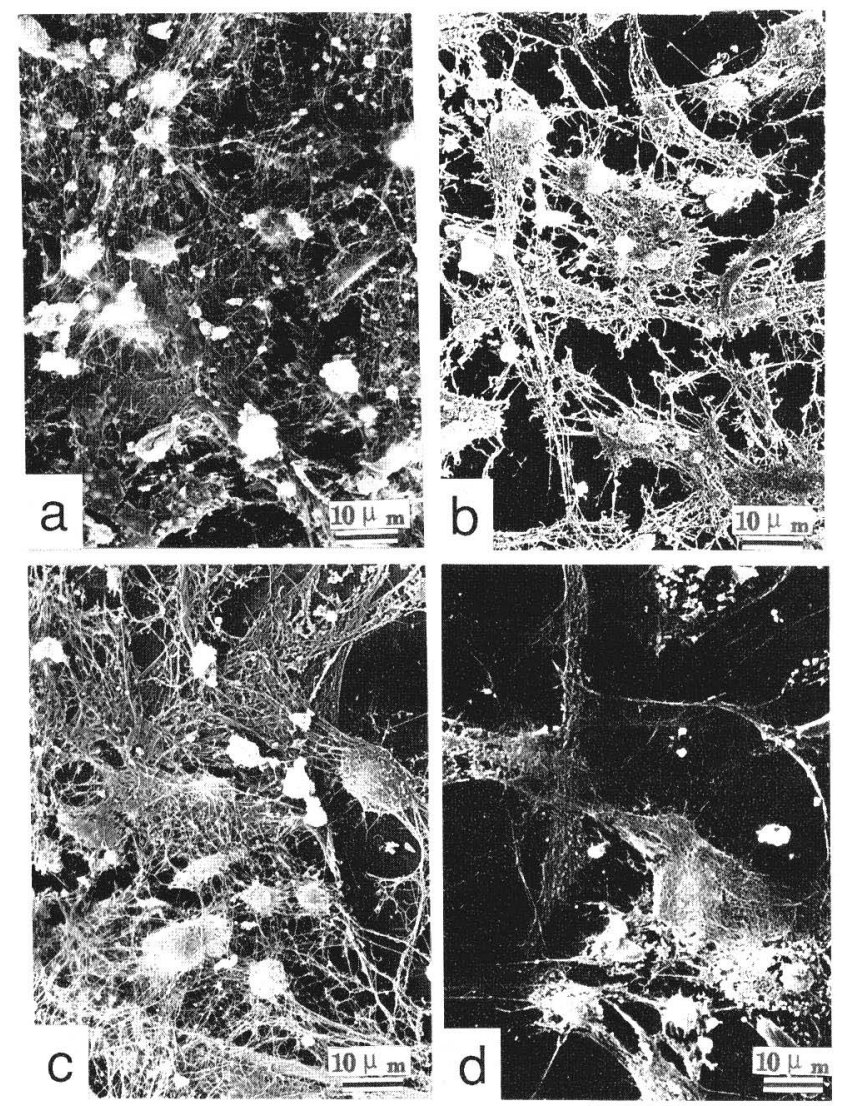

Fig. 4. Ultrastructure of chicken embryonic chondrocytes. The cells were cultured for 4 days in media containing different concentrations of T-2 toxin. (a) Control: Showing cytoskeleton and collagen microfibrils in extracellular matrix of chondrocytes in non-supplemented medium. (b) Addition of $0.01 \mathrm{ppm} \mathrm{T-2} \mathrm{toxin:} \mathrm{Showing} \mathrm{significant}$ decrease in collagen microfibril amount. (c) Addition of 0.004 ppm T-2 toxin: Showing cytoskeleton and collagen microfibrils similar to those of control. (d) Addition of 0.04 ppm T-2 toxin: Showing a lowered density of chondrocytes, a destroyed cytoskeleton, and a decrease in collagen microfibril amount in the matrix. 
were added respectively to the medium; and the chondrocytes were then cultured for 4 days.

Figure 4(a) shows the control, where the collagen microfibrils in the extracellular matrix cross link one another to form a filament network. Figure 4(c) depicts the result when $0.004 \mathrm{ppm}$ toxin was added to the medium used to culture the chondrocytes. There was no significant change compared with the control. However, when $0.01 \mathrm{ppm}$ T-2 toxin was added, the extracellular collagen microfibrils showed an obvious decrease (Fig. 4(b)). And when 0.04 ppm T-2 toxin was added, striking changes were found: the density of chondrocytes had become lower, the extracellular collagen microfibrils had decreased, and the cytoskeleton had been destroyed (Fig. 4(d)).

It is known that cytochrome $c$ oxidase and succinic dehydrogenase are marker enzymes of the mitochondrial inner membrane and that $\mathrm{H}^{+}$-ATPase is the key enzyme for the coupling of oxidative phosphorylation. Table 1 shows that the specific activity of mitochondrial cytochrome $c$ oxidase decreased rapidly when $0.004 \mathrm{ppm}$ T-2 toxin was present in the medium. However, the specific activity remained at the same level when the toxin was increased to 0.01 and $0.04 \mathrm{ppm}$. In the case of succinic dehydrogenase, there was no change in specific activity when $0.004 \mathrm{ppm}$ T-2 toxin was present in the medium; and when the toxin was increased to 0.01 and $0.04 \mathrm{ppm}$, the specific activity only decreased slightly. Table 2 indicates that the specific activity of $\mathrm{H}^{+}$-ATPase in the presence of $0.004 \mathrm{ppm} \mathrm{T-2}$ toxin was near the control value but that it is decreased to 72.0 and $62.1 \%$ of the control when the $\mathrm{T}-2$ toxin was increased to 0.01 and $0.04 \mathrm{ppm}$, respectively. It was reported that $\mathrm{T}-2$ toxin inhibits mitochondrial respiration of rat liver and that in vivo experiments a large dose of T-2 toxin could inhibit the oxidation of succinic and pyruvic

Table 1. Effect of different concentrations of T-2 toxin on mitochondrial cytochrome $c$ oxidase and succinate dehydrogenase activities of cultured chicken embryonic chondrocytes.

\begin{tabular}{|c|c|c|c|c|c|}
\hline & \multicolumn{4}{|c|}{$\mathrm{T}-2$ toxin $(\mathrm{ppm})$} & \multirow{2}{*}{$\begin{array}{c}\text { Comparison } \\
t \text {-test }\end{array}$} \\
\hline & Control (1) & $0.004(2)$ & $0.01(3)$ & $0.04(4)$ & \\
\hline $\begin{array}{l}\text { Cytochrome } c \text { oxidase } \\
\left(k^{*} / \mathrm{mg} \text { protein }\right)\end{array}$ & $\begin{array}{r}1.633 \\
\pm 0.174\end{array}$ & $\begin{array}{r}1.113 \\
\pm 0.040\end{array}$ & $\begin{array}{r}1.151 \\
\pm 0.091\end{array}$ & $\begin{array}{r}1.103 \\
\pm 0.294\end{array}$ & $\begin{array}{c}\text { (1) vs. (2) } \\
p<0.01 \\
\text { (1) vs. (3) } \\
p<0.02 \\
\text { (1) vs. (4) } \\
p<0.1\end{array}$ \\
\hline $\begin{array}{l}\text { Succinate dehydrogenase } \\
\text { (nmol succinate } \\
\text { oxidized } / \mathrm{min} / \mathrm{mg} \\
\text { protein) }\end{array}$ & $\begin{array}{r}4.13 \\
\pm 1.79\end{array}$ & $\begin{array}{r}4.89 \\
\pm 1.41\end{array}$ & $\begin{array}{r}3.70 \\
\pm 0.61\end{array}$ & $\begin{array}{r}3.44 \\
\pm 1.99\end{array}$ & $\begin{array}{l}\text { (1) vs. (2) } \\
\text { NS } \\
\text { (1) vs. (3) } \\
\text { NS } \\
\text { (1) vs. (4) } \\
\text { NS }\end{array}$ \\
\hline
\end{tabular}

Values are mean $\pm \mathrm{SD}(n=3) .{ }^{*} k$ refers to the initial first-order rate constant expressed in $\min ^{-1}$. 
acids of rat liver mitochondria [20]. These results were similar to ours. Thus, T-2 toxin inhibits the energy metabolism of cells.

\section{Antagonistic effect of Se on T-2 toxin-induced changes in chondrocytes}

In the preparation of specimens for SEM observation, due to the treatment with Triton X-100 for 15 min the plasma membrane of the chondrocytes disappeared and most of the organelles flowed out from the cell to allow the whole cytoskeleton and extracellular matrix to be easily seen. Examples of control specimens with abundant network formed by cytoskeleton and collagen microfibrils of extracellular matrix are shown in Fig. 5(a), (b). Figure 5(c), (d) demonstrate a significant decrease in the amount of collagen microfibrils in the matrix of cultured chondrocytes but no change in the cytoskeleton in the presence of 0.01 ppm T-2 toxin. In the co-presence of $0.01 \mathrm{ppm} \mathrm{T-2} \mathrm{toxin} \mathrm{and} 1 \mathrm{ppm} \mathrm{Na}_{2} \mathrm{SeO}_{3}$, the network of cytoskeleton and extracellular collagen microfibrils were richer than that in the presence of $0.01 \mathrm{ppm}$ T-2 toxin alone, having the same appearance as the control. It is known that the chondrocytes possess the capacity of synthesizing and secreting collagen microfibrils, which, in turn, play an important role in the maintenance of the morphology, growth, and development of chondrocytes. This implies an interaction between extracellular matrix and intracellular cytoskeleton. Our experimental results indicate that the inhibition of collagen synthesis and secretion induced by $0.01 \mathrm{ppm} \mathrm{T-2}$ toxin can be antagonized by $1 \mathrm{ppm} \mathrm{Na}_{2} \mathrm{SeO}_{3}$ to keep the collagen microfibrils network in the normal state.

Antagonism by Se was also found with respect to IMP distribution. Figure 6(a) shows a typical control specimen with an evenly dense distribution of IMPs on the P-face of the chondrocytic plasma membrane. Figure 6(b), (c) illustrate the Se-induced recovery of the normal IMP pattern that was disrupted by $0.01 \mathrm{ppm} \mathrm{T-2}$ toxin. It is well known that biological membranes contain a variety of peripheral and integral proteins. Freeze-fracture electron microscopy is a valuable technique for ascertaining the membrane proteins which are located in the interior of biological membrane. The membrane proteins are responsible for most of the dynamic processes carried out by the membranes; and specific proteins mediate

Table 2. Effect of different concentration of T-2 toxin on mitochondrial $\mathrm{H}^{+}$-ATPase of cultured chicken embryonic chondrocytes.

\begin{tabular}{lccccc}
\hline & \multicolumn{3}{c}{ Concentration of T-2 toxin } & Comparison \\
\cline { 2 - 5 } & Control & $0.004 \mathrm{ppm}$ & $0.01 \mathrm{ppm}$ & $0.04 \mathrm{ppm}$ & $\begin{array}{c}t \text {-test } \\
\end{array}$ \\
& $(1)$ & $(2)$ & $(3)$ & $(4)$ & \\
\hline Specific activity & 0.13 & 0.146 & 0.095 & 0.082 & $(1)$ vs. (2) \\
$(\mu$ mol ATP hydrolyzed/ & \pm 0.01 & \pm 0.018 & \pm 0.004 & \pm 0.014 & NS \\
min/mg protein) & $(n=6)$ & $(n=4)$ & $(n=4)$ & $(n=4)$ & $(1)$ vs. (3) \\
& & & & & $p<0.001$ \\
& & & & $(1)$ vs. (4) \\
& & & & $p<0.001$ \\
\hline
\end{tabular}

\footnotetext{
Values are mean $\pm \mathrm{SD}$
} 

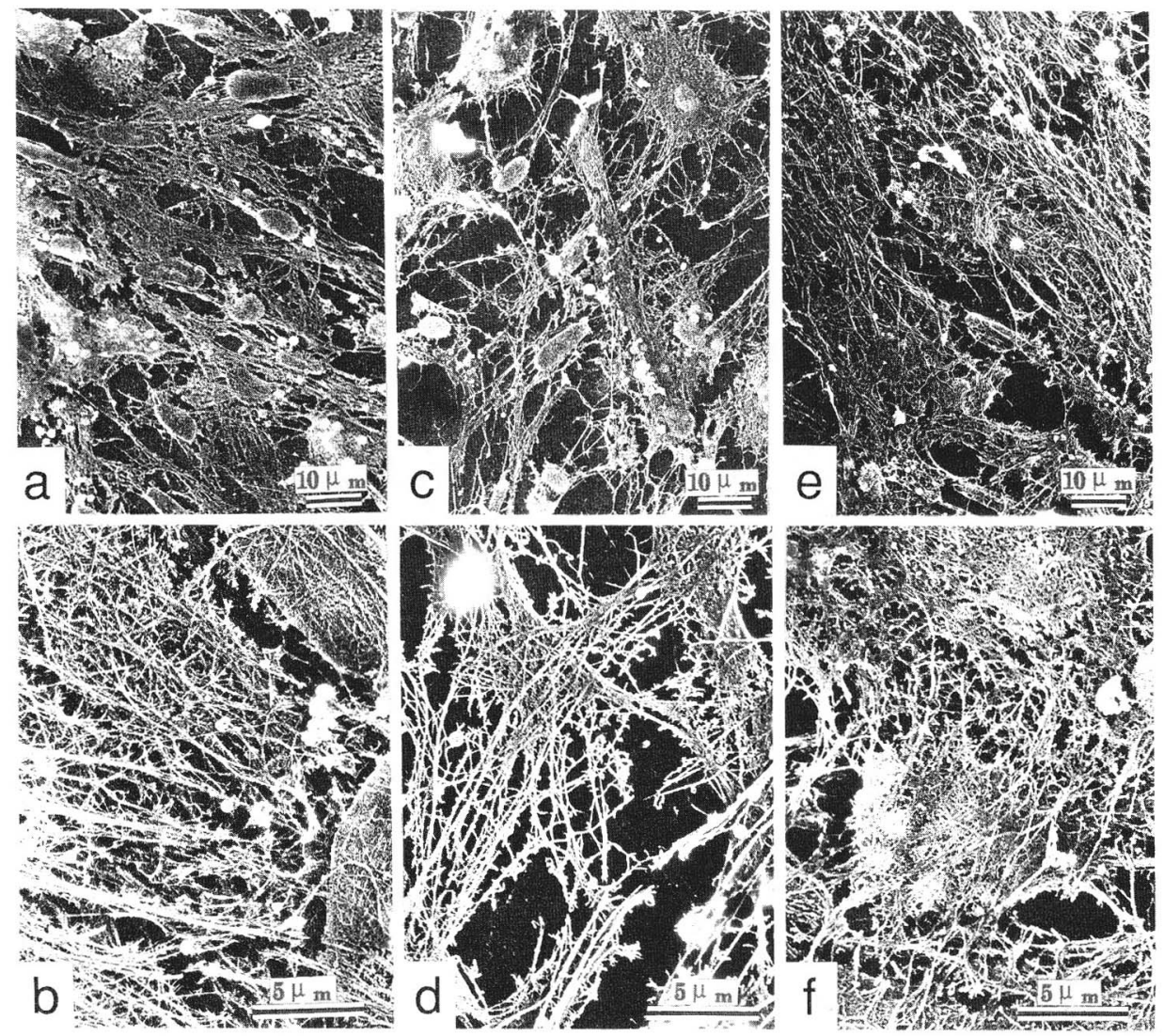

Fig. 5. Antagonistic effect of Se on the changes in the ultrastructure of chicken embryonic chondrocytes induced by $0.01 \mathrm{ppm}$ T-2 toxin, as seen by SEM at different magnifications. (a) and (b) Control: Showing cytoskeleton and collagen microfibrils in the matrix of chondrocytes in non-supplemented medium. (c) 0.01 ppm T-2 toxin added: Showing the decrease in collagen microfibril amount in the matrix and no significant change in the cytoskeleton. (d) The same specimen as shown in photomicrograph c, showing the obvious decrease in collagen microfibril amount in the matrix. (e) and (f) $1 \mathrm{ppm}$ $\mathrm{Na}_{2} \mathrm{SeO}_{3}$ and $0.01 \mathrm{ppm}$ T-2 toxin added: Showing collagen microfibril amount in the matrix similar to that in the control.

distinctive membrane functions, such as transport, communication, and energy transduction. The decrease in IMP number induced by $0.01 \mathrm{ppm}$ of T-2 toxin implies that the biosynthesis of membrane proteins of chondrocytes is inhibited by the toxin at this concentration. It was reported in 1981 by Lafarge-Frayssinet et al. [21] that T-2 toxin, a trichothecene metabolite of Fusarium, could inhibit both protein and DNA biosynthesis. Our experimental results further indicate that the $1 \mathrm{ppm} \mathrm{Na}_{2} \mathrm{SeO}_{3}$ can antagonize the harmful effects exerted by $\mathrm{T}-2$ toxin on biosynthesis of membrane protein. The damaging effect of T-2 toxin is not only on membrane protein and mitochondrial function of chondrocytes but also on organ 

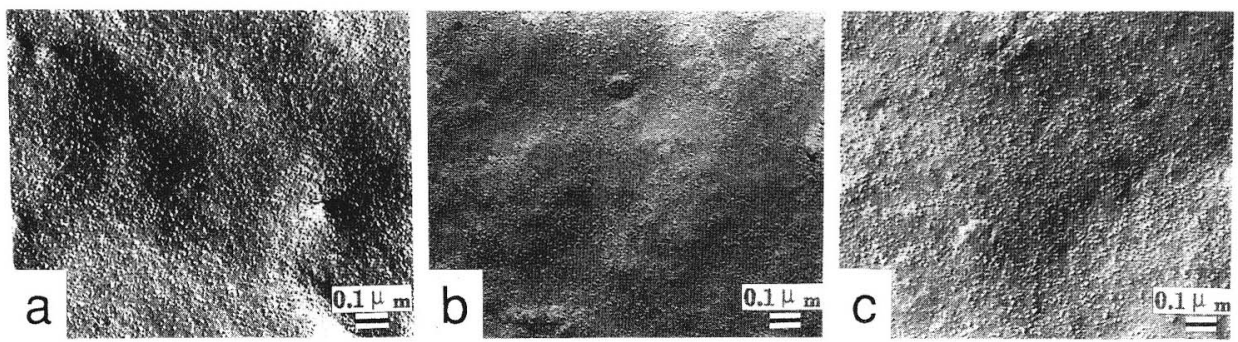

Fig. 6. Antagonistic effect of $\mathrm{Se}$ on the changes in the ultrastructure of chicken embryonic chondrocytes induced by $0.01 \mathrm{ppm} \mathrm{T-2} \mathrm{toxin,} \mathrm{as} \mathrm{seen} \mathrm{by} \mathrm{freeze-fracture} \mathrm{TEM} \mathrm{observa-}$ tion. (a) Control: Showing IMPs (intramembrane particles) on the P-face of the plasma membrane in the normal distribution. (b) $0.01 \mathrm{ppm} \mathrm{T-2} \mathrm{toxin} \mathrm{added:} \mathrm{Showing} \mathrm{obvious}$ reduction in IMP number. (c) 1 ppm $\mathrm{Na}_{2} \mathrm{SeO}_{3}$ and $0.01 \mathrm{ppm} \mathrm{T-2}$ toxin added: Showing distribution of IMPs similar to that of the control.

Table 3. Antagonistic effect of Se on the T-2 toxin-induced changes in the activities of cytochrome $c$ oxidase and succinate dehydrogenase.

\begin{tabular}{|c|c|c|c|c|}
\hline & \multicolumn{3}{|c|}{ Treatment } & \multirow{2}{*}{$\begin{array}{c}\text { Comparison } \\
t \text {-test }\end{array}$} \\
\hline & $\begin{array}{l}\text { Control } \\
\text { (1) }\end{array}$ & $\begin{array}{l}0.01 \mathrm{ppm} \\
\mathrm{T}-2(2)\end{array}$ & $\begin{aligned} & 1 \mathrm{ppm} \mathrm{Na}_{2} \mathrm{SeO}_{3} \\
+ & 0.01 \text { ppm T-2 (3) }\end{aligned}$ & \\
\hline $\begin{array}{l}\text { Cytochrome } c \text { oxidase } \\
\left(k^{*} / \mathrm{mg} \text { protein }\right)\end{array}$ & $\begin{array}{r}2.098 \\
\pm 0.111\end{array}$ & $\begin{array}{r}1.220 \\
\pm 0.131\end{array}$ & $\begin{array}{r}1.585 \\
\pm 0.088\end{array}$ & $\begin{array}{l}\text { (1) vs. (2) } \\
p<0.001 \\
\text { (2) vs. (3) } \\
p<0.001\end{array}$ \\
\hline $\begin{array}{l}\text { Succinate dehydrogenase } \\
\text { (nmol succinate oxidized/ } \\
\mathrm{min} / \mathrm{mg} \text { protein) }\end{array}$ & $\begin{array}{r}6.85 \\
\pm 1.62\end{array}$ & $\begin{array}{r}6.32 \\
\pm 1.09\end{array}$ & $\begin{array}{r}6.78 \\
+1.03\end{array}$ & $\begin{array}{l}\text { (1) vs. (2) } \\
\text { NS } \\
\text { (2) vs. (3) } \\
\text { NS }\end{array}$ \\
\hline
\end{tabular}

Values are mean $\pm \mathrm{SD}(n=5) .{ }^{*} k$ refers to the initial first-order rate constant expressed in $\min ^{-1}$.

malformation and carcinogenesis. The toxicology of T-2 toxin was reviewed recently by Yang et al. [22]. Similar effect of trichothecene mycotoxins other than T-2 toxin, such as deoxynivalenol, on articular chondrocytes has been reported [23].

Table 3 shows that $0.01 \mathrm{ppm}$ T-2 toxin significantly reduced the cytochrome $c$ oxidase activity down to a level of only $58 \%$ of the activity in the control. When $0.01 \mathrm{ppm}$ toxin was added to the medium containing $1 \mathrm{ppm} \mathrm{Na}_{2} \mathrm{SeO}_{3}$ the reduction of cytochrome $c$ oxidase activity was not as much as when no Se was present in the medium. It reached $76 \%$ of the activity of control. This shows that Se can antagonize part of the activity decrease induced by T-2 toxin. Neither T-2 toxin nor it plus Se had a noticeable effect on succinic dehydrogenase activity (Table 3 ). Table 4 indicates the antagonistic effect of Se on the T-2 toxin-induced decreases in $\mathrm{H}^{+}$-ATPase activity and oligomycin sensitivity of the enzyme. A concentratin of 
Table. 4. Antagonistic effect of Se on the T-2 toxin-induced decrease in activity of $\mathrm{H}^{+}$-ATPase and in sensitivity to oligomycin of $\mathrm{H}^{+}$-ATPase.

\begin{tabular}{lcccc}
\hline & $\begin{array}{c}\mathrm{H}^{+} \text {-ATPase } \\
(\mu \text { mol ATP } \\
\text { hydrolyzed } / \mathrm{min} / \\
\text { mg protein })\end{array}$ & $\begin{array}{c}\text { Comparison } \\
t \text {-test }\end{array}$ & $\begin{array}{c}\text { Oligomycin } \\
\text { inhibition }(\%)\end{array}$ & $\begin{array}{c}\text { Comparison } \\
t \text {-test }\end{array}$ \\
& $0.219 \pm 0.079$ & $(1)$ vs. $(2)$ & $59.06 \pm 16.8$ & $(1)$ vs. $(2)$ \\
(1) Control & $(n=9)$ & $p<0.02$ & $(n=9)$ & $p<0.02$ \\
(2) $0.01 \mathrm{ppm} \mathrm{T}-2$ & $0.118 \pm 0.023$ & $(2)$ vs. $(3)$ & $29.52 \pm 11.4$ & $(2)$ vs. $(3)$ \\
& $(n=5)$ & $p<0.001$ & $(n=5)$ & $p<0.001$ \\
(3) 1 ppm Na $\mathrm{SeO}_{3}$ & $0.213 \pm 0.018$ & & $56.12 \pm 1.92$ & \\
and $0.01 \mathrm{ppm} \mathrm{T}^{2}$ & $(n=5)$ & & $(n=5)$ & \\
\hline
\end{tabular}

Values are mean \pm SD.

0.01 ppm of T-2 toxin reduced $\mathrm{H}^{+}$-ATPase activity to about $54 \%$ of the activity in the control, and the oligomycin sensitivity was reduced to about half of the control. When both $1 \mathrm{ppm} \mathrm{Na}_{2} \mathrm{SeO}_{3}$ and $0.01 \mathrm{ppm} \mathrm{T-2}$ toxin were added to the culture medium, the $\mathrm{H}^{+}$-ATPase activity was increased from 54 to $97 \%$ of the control; and the oligomycin sensitivity was also increased from about 50 to $95 \%$ of the control. These results clearly indicate that Se can antagonize the $\mathrm{H}^{+}$-ATPase activity and oligomycin sensitivity decreased by the toxin. We can thus conclude that 1 ppm $\mathrm{Na}_{2} \mathrm{SeO}_{3}$ can obviously antagonize the T-2 toxin-induced changes in ultrastructure and energy transduction function of mitochondria of chondrocytes. Furthermore, the mechanism underlying the preventive effect of Se on KBD formation appears to be this antagonizing effect of Se. Wang et al. [24] reported that free radicals induce abnormalities of chondrocytes, its matrix, and mineralization. The antagonistic effect of Se can also be interpreted as an effect to overcome the excessive accumulation of free radicals by means of increasing the activities of glutathione peroxidase (GSHPx) and phospholipid hydroperoxide glutathione peroxidase (PHGPx), which are a kind of seleno-protein and play an important role in the free radical scavenging. It was reported that T-2 toxin may also lead to accelerate the lipid peroxidation [25]. Further studies on the mechanism of antagonistic effect of Se on the action of $\mathrm{T}-2$ toxin are in progress.

We would like to thank Prof. Jin-Sheng Yang for kindly providing the T-2 toxin and for helpful discussions.

\section{REFERENCES}

1. Yang, J.B. (1983): Progress in the study of Kaschin Beck disease caused by mycotoxin. Chin. J. Endemiol., 3, 155 (in Chinese).

2. An, M.Y., Cu, Q.L., Guan, D.M., and Liu, Y.Q. (1984): Examination of fungi in corn and wheat of endemic area Yong-Shou County, China, in Collected Works of Scientific Survey on Kaschin Beck Disease in Yong-Shou Prefecture, China, ed. by Leading Group of Control of Endemic Disease of Chinese Government, Publishing House of People's 
Hygiene, Beijing, pp. 46-49 (in Chinese).

3. Luo, Y., Zheng, J.S., Yang, J.S., Liu, F., Yoshizawa, T., Zhang, C.Y., Zhang, B.J., Liu, K.C., Zhai, S.S., Sha, R., and Wen, H. (1992): Determination of Fusarium Mycotoxin in corn and wheat from Kaschin Beck Disease Area. Chin. J. Contr. Endem. Dis., 7, 71-75 (in Chinese).

4. Ronald, C.S. (1980): Mycotoxins and N-nitroso compounds. Envmt. Risks, 2, 40.

5. Tan, J.A., Zheng, D.X., Hou, S.F., Zhu, W.Y., Li, R.B., Zhu, Z.Y., and Wang, W.Y. (1987): Selenium ecological chemical geography and endemic Keshan Disease and Kaschin Beck Disease in China, in Selenium in Biology and Medicine, ed. by Combs, G.F., Jr., Spallholz, J.E., Levander, O.A., and Oldfield, G.E., Van Nostrand Reinhold, New York, pp. 859-876.

6. Mo, D.X. (1987): Pathology and selenium deficiency in Kaschin Beck disease, in Selenium in Biology and Medicine, ed. by Combs, G.F., Jr., Spallholz, J.E., Levander, O.A., and Oldfield, G.E., Van Nostrand Reinhold, New York, pp. 924-933.

7. Li, C.Z., Huang, J.R., and Li, C.X. (1987): Sodium selenite as a preventive measure for KBD as evaluated in X-ray studies, in Selenium in Biology and Medicine, ed. by Combs, G.F., Jr., Spallholz, J.E., Levander, O.A., and Oldfield, G.E., Van Nostrand Reinhold, New York, pp. 934-937.

8. Liang, S.T. (1984): Study on the control of Kaschin Beck diseae by $\mathrm{Na}_{2} \mathrm{SeO}_{3}$, in Collected Works of Scientific Survey in Yong Shou Prefecture, China, ed. by Leading Group of Control of Endemic Disease of Chinese Government, Publishing House of People's Hygiene, Beijing, pp. 142-147 (in Chinese).

9. Wo, W.H., and Yang, F.Y. (1986): Protective effect of Se on erythrocyte membrane. Sci. Sin. Ser. B, XXIX, 1179-1185.

10. Yang, F.Y., and Wo, W.H. (1987): Role of Se in stabilization of human erythrocyte membrane skeleton. Biochem. Int., 15, 475-482.

11. Wang, W.Z., Chen, B.N., Qiao, Y.J., Cui, Z.G., and San, Z.H. (1982): A modified primary monolayer culture of embryonic chicken leg chondrocytes in vitro. Chin. J. Endemiol., 1, 271-274.

12. Zhou, Q.S., Ding, M.X., Wang, X., Chen, L.H., Zhai, Z.H., Men, S.Q., and Xu, W. (1986): Several simple methods of applying EM to study the relationship between cytoskeletons and viruses. J. Chin. Electron Microsc. Soc., 5, 6.

13. Hwang, F., Wang, S.M., and Mu, C.C. (1983): The disordering effect of hyoscyamine drugs on phospholipid membranes. Biochim. Biophys. Acta, 736, 220-225.

14. Smith, L. (1955): Spectrophotometric assay of cytochrome $c$ oxidase. Methods Biochem. Anal, 2. 427-434.

15. Kim, I., and Beattie, D.S. (1973): Formation of the yeast mitochondrial membrane 1. Effect of inhibition of protein synthesis on the kinetics of enzyme appearance using glucose derepression. Eur. J. Biochem., 36, 509-518.

16. Li, S.G., and Sun, S. (1983): Spectroscopic determination of ATPase activity. Biochem. Biophys., 6, 70-71 (in Chinese).

17. Mertz, W. (1981): The essential trace elements, Science, 213, 1332-1348.

18. Yang, J., and Yang, F.Y. (1990): Concentration dependence of Se effect on the stabilization of human erythrocyte membrane. Chin. Biochem. J., 6, 141-146.

19. Wu, L.Y., Sun, S., Ji, H.F., Lin, Z.H., and Yang, F.Y. (1991): Concentration dependence of Se effect on the cytoskeleton and collagen microfibrils of chicken embryo chondrocyte and its extracellular matrix. Chin. Sci. Bull., 36, 1834-1836.

20. Pace, J.G. (1983): Effect of T-2 mycotoxin on rat liver mitochondria electron transport system. Toxicon, 21, 675-680.

21. Lafarge-Frayssinet, C., Decloitre, F., Mousset, S., Martin, M., and Frayssinet, C. (1981): Induction of DNA single-strand breaks by T-2 toxin, a trichothecene metabolite of Fusarium. Effect on lymphoid organs and liver. Mutat. Res., 88, 115-123.

22. Yang, J.S., Kuang, K.Y., Li, C.D., Gu, D.X., Ma, Q.Y., and Luo, Y. (1993): T-2 toxin, in Bacteriotoxins, Vol. 3, ed. by Luo, H.P., Yang, J.Y., and Bao, X.H., Beijing Medical 
University and China Union Medical University Joint Press, Beijing, pp. 323-347 (in Chinese).

23. Peng, S.Q., Yu, X.L., Wang, B.Z., Yang, Y., Zheng, Z.F., and Yang, J.S. (1994): Toxic effects of deoxynivalenol on articular chondrocytes and the protective effect of selenium. Chin. J. Endemiology, 13, 80-82 (in Chinese).

24. Wang, K., Xu, S.J., Zhang, F.H., Wang, C.X., Cheng, T.R., Chang, S.Y., Wu, L., Zhang, J.X., Yang, Z.H., Shu, Y.X., and Zhang, J.Y. (1990): Abnormal chondrocytes, matrix and abnormal mineralization induced by free radical. Chin. J. Contr. Endem. Dis., 5, 5-8 (in Chinese).

25. Tang, J.J., and Rui, H.F. (1989): The effect of Moniliformin on lipid peroxidation and a protective effect of selenium in mouse. Environ. Chem., 8, 23-26. 